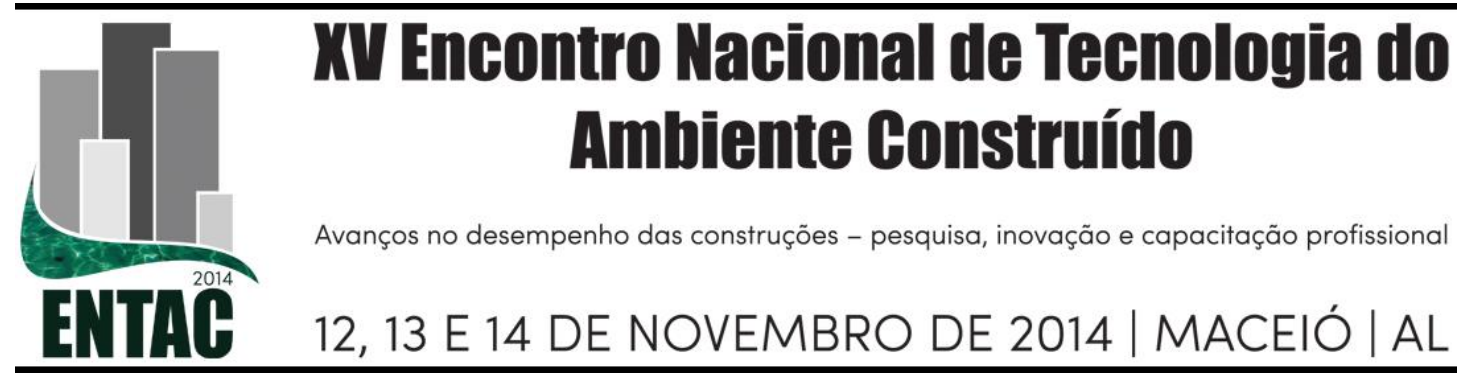

\title{
MÁSCARA DE OBSTRUÇÃO: USO DE NOVAS TECNOLOGIAS QUE FACILITAM A VERIFICAÇÃO DA OBSTRUÇÃO DO CÉU VISÍVEL
}

\author{
AMORIM, Rafael Ponce de Leon (1); PEDROSA, Maria Luiza (2); CARVALHO, \\ Homero Jorge Matos (3) \\ (1) IFPB, e-mail: rafael.ponce@ifpb.edu.br (2) IFPB, e-mail: pedrosamarialuiza@hotmail.com, (3) IFPB, \\ e-mail: homerojmc@gmail.com
}

\begin{abstract}
RESUMO
A carta solar é uma importante ferramenta para a compreensão da geometria da insolação e a sua interação com o espaço construído, tornando-se fundamental para o projeto bioclimático. Porém apesar da aparente facilidade de utilização dos métodos disponíveis, analíticos (gráficos), fotográficos ou modelagens computacionais, percebe-se a pouca utilização desta ferramenta na rotina projetual dos estudantes e profissionais de arquitetura. Neste sentido, este trabalho apresenta os resultados de uma pesquisa que teve como objetivo verificar a confiabilidade de duas ferramentas utilizadas para a determinação da máscara de obstrução da abóbada celeste pelas edificações. A primeira refere-se ao software Sketchup PRO 8 em conjunto com dois plug-ins, V-ray e SunTools; o segundo, à utilização de uma lente olho-de-peixe acoplada a um dispositivo móvel, celular ou tablet. As máscaras de obstrução resultantes da aplicação dessas duas ferramentas foram comparadas às máscaras obtidas através da utilização do software Autodesk ECOTECT 2011 e desenhadas com o auxílio do software Autodesk AutoCAD 2012. Em todos os casos o método utilizado para a produção das máscaras foi o estereográfico. Constatou-se que: as duas ferramentas verificadas produzem resultados satisfatórios; a máscara produzida com a lente olho de peixe tem a vantagem de incluir a vegetação arbórea entre os elementos de obstrução da abóbada celeste e; geralmente são desconsideradas no uso das demais ferramentas. A presente pesquisa, caracterizada como analítica, é resultado de atividades experimentais e didáticas do Laboratório de Conforto do Ambiente do Curso Superior de Tecnologia de Design de Interiores do Instituto Federal Educação, Ciência e Tecnologia da Paraíba - IFPB, e espera contribuir com a incorporação da geometria da insolação na prática projetual, ao facilitar o uso de duas ferramentas que já estão disponíveis aos projetistas em seu dia-a-dia.
\end{abstract}

Palavras-chave: geometria da insolação, lente olho-de-peixe, Sketchup.

\begin{abstract}
The solar chart is an important tool to the comprehension of the solar geometry and its interaction with the built space, what makes this chart fundamental to the bioclimatic project. However, despite of the facility appearance of the available methods such as analytics, photographic, computing modeling, it is visible almost no one utilization that tool during project routine of the architecture students and professionals. In this sense, this article presents the results of a survey that aimed to verify the reliability of the two instruments used to determine the shadow mask of the buildings. The first refers to Sketchup Pro 8 software with two plug-ins, V-ray and SunTools. The second concerns the use of a fish-eye lens attached to a mobile device, cell phone or tablet. The shadow masks resulting from the application of these two tools were compared to the masks obtained by using Autodesk software 2011 ECOTECT and designed with the help of Autodesk AutoCAD 2012 software. In all cases the method used for the production of masks was the stereographic. It was realized that: the two verified tools produce satisfactory results; mask produced with the fish-eye lens has the advantage of including vegetation between the elements of obstruction of the celestial vault, usually are not considered in use the others tools. This research, characterized as analytical,
\end{abstract}


is results of experimental and didactic activities of the Laboratory of Environmental Comfort, which belongs to the Technology Course of Interior Design from the Federal Institute Education, Science and Technology of Paraíba (IFPB), and aims to contribute to the insertion of the insolation geometry in project practice, providing the designer two tools that are already part of your day-to-day.

Keywords: Solar Geometry, Fish-eye lens, Sketchup.

\section{INTRODUÇÃO}

A carta solar relacionada com as máscaras de obstrução (pelas edificações) da abóbada celeste é um recurso bastante útil e simples para verificação do fator de visão do céu, do período de exposição à radiação solar, da estimativa da quantidade de radiação direta e difusa de um determinado ponto situado no meio urbano, gerando subsídios para a avaliação e o projeto de edificações e espaços abertos no meio urbano. Pode, portanto, ser utilizada em diferentes escalas e setores do desenho urbano (projeto viário, implantação de arborização, definição da relação entre altura e afastamento das edificações etc) e da arquitetura (implantação e orientação dos edifícios, orientação e dimensionamentos das aberturas e elementos de sombreamento, cálculo de carga térmica.

De acordo com Bittencourt (2004), a cartas solar, também conhecidas por diagrama solar ou gráfico solar, é a representação gráfica, em um plano horizontal, do percurso do sol na abóbada celeste da terra nos diferentes períodos do dia e do ano. Enquanto a máscara de sombra refere-se à inclusão, na carta solar, dos obstáculos que impedem a visão da abóbada celeste por um observador, tais como, os edifícios e os elementos arbóreos do entorno.

Atualmente diversos métodos são utilizados para a verificação da obstrução do céu visível, desde ferramentas mais tradicionais como o método gráfico auxiliado por softwares do tipo CAD, fotografias com lentes do tipo olho-de-peixe, e, por fim, simulações em softwares específicos, tais como Autodesk Ecotect, Solar Tool, Sun Path e Sol-ar.

Os métodos gráficos e computacionais dependem de um amplo levantamento físico inicial do local a ser avaliado e seu entorno, além da dificuldade de inserção dos elementos arbóreos, enquanto a fotografia com a lente olho-de-peixe permite uma rápida verificação do entorno com todos os seus elementos, mas que por outro lado exige um alto investimento financeiro para a aquisição de uma câmera e a lente olho-de-peixe. Estas dificuldades muitas vezes impossibilitam a adoção dessas ferramentas por alunos e profissionais do mercado de arquitetura e urbanismo.

Neste sentido, o presente artigo visa demonstrar a viabilidade de utilização de duas diferentes ferramentas que podem auxiliar na fase de projeto de forma mais prática e rápida. O primeiro método analisa a utilização do software Sketchup em conjunto com dois plug-ins, V-ray e Sun Tool, e, o segundo, refere-se à utilização de uma lente olho-depeixe para dispositivos móveis, tais como smartphones e tablets.

\section{MÉTODOS E INSTRUMENTOS PARA A PRODUÇÃO DA MÁSCARA E OBSTRUÇÃO DO CÉU E CÁLCULO DO FATOR DE VISÃO DO CÉU}

A máscara de obstrução obtida em um determinado ponto, sobreposta ao diagrama solar, permite ao projetista analisar os horários e períodos de insolação e auxiliam na tomada de decisões na fase projetual.

Para se obter a máscara de obstrução do céu, em primeiro instante, é necessário reproduzir a projeção da abóbada celeste (céu) no plano horizontal. Para isso, entre os métodos 
existentes (ortográfica, equidistante, gnomônica e estereográfica), o de projeção esteorográfica é o mais preciso. No caso da projeção estereográfica, são adicionados os conceitos de zênite e nadir. O zênite corresponde ao ponto mais alto da abóbada celeste, enquanto o nadir refere-se ao ponto oposto, e coincide com o ponto ocupado pelo observador. Nessa projeção, o nadir é o foco, para onde convergem as linhas de projeção dos pontos localizados na abóbada. De acordo com Souza (2003, p.32), as "distorções em áreas e formas próximas à linha do horizonte existem, porém são menores, e a distorção na escala também aumenta no sentido do centro à linha do horizonte".

A aludida autora cita Whittaker (1997) para dizer que a projeção estereográfica, por muitas razões, é a melhor maneira de representar em um plano as relações entre o céu e a Terra. Isso porque "garante que qualquer ponto projetado ou transferido para a abóbada celeste estará necessariamente projetado no interior do círculo de projeção no plano horizontal, seja qual for o diâmetro adotado para a projeção". Por fim, Frota (2004) acrescenta que o método de projeção estereográfico é o mais utilizado.

A máscara de obstrução solar é a representação gráfica dos obstáculos que impedem a visão da abóbada celeste a partir de um observador localizado em um lugar qualquer. Já a fração visível do céu é denominada Fator de Visão do Céu (FVC) (Figura 01).

Figura 01: Obstrução causada pela edificação Fonte: Yamaguti (2007 apud SOUZA, 2003)

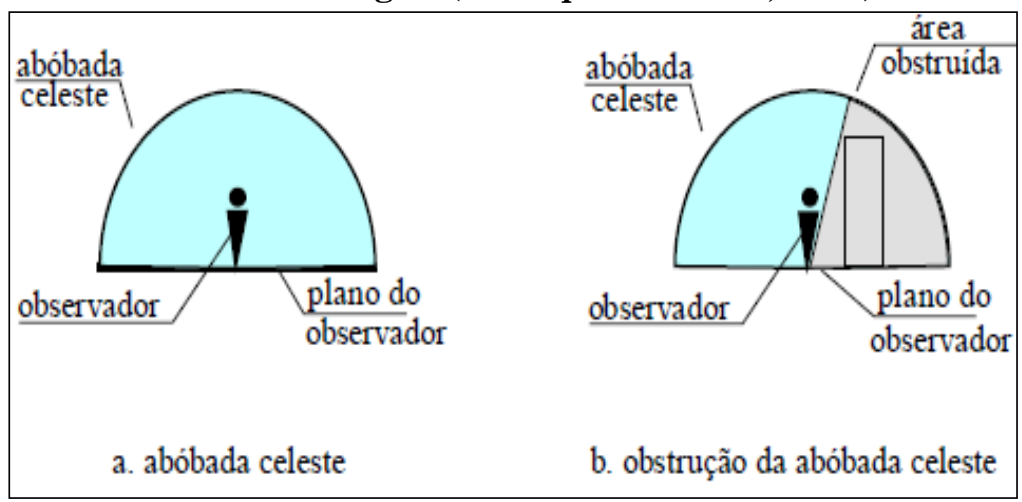

Segundo Souza (2003, p.39), o FVC pode ser estimado por vários métodos (processos), dos quais se destacam os processos analíticos (matemáticos), por fotografia, por processamento de imagens, por diagramas ou por gráficos. Tanto pelo processo analítico, como pelo uso de diagramas e gráficos, é necessária uma base de dados angulares relativos às edificações existentes no entorno urbano.

Para a avaliação comparativa das ferramentas sugeridas neste trabalho para a produção automatizada de máscaras de obstrução, tomou-se como referência uma máscara de obstrução desenhada em CAD, cujo procedimento de produção pode ser conhecido em Frota (2004).

Para Chapaman, Thornes e Bradley (2002), o método gráfico sofre, frequentemente, aproximações e estimativas. Portanto, para se obter um resultado mais preciso é necessária uma imagem gerada por uma lente do tipo "olho de peixe", cujo custo, como já foi dito, é elevado. A lente "olho de peixe" possui uma abertura angular de $180^{\circ} \mathrm{e}$ produz uma imagem em projeção estereográfica. Para gerar a obstrução, ela deve ser acoplada a uma câmera fotográfica, ser apontada para cima e ter um aparato provido de bússola e nível (GRAZZIOTIN, 2003, p. 46; VILELA, 2007, p. 90). Daí a necessidade de se desenvolver técnicas e instrumentos mais acessíveis, seja quanto à operação, seja quanto ao custo e tempo de produção. 
Neste sentido, nos últimos anos, algumas pesquisas buscaram o desenvolvimento de técnicas e ferramentas de automatização dos processos de obtenção das máscaras de obstrução. Outras buscaram utilizar e/ou adaptar equipamentos e técnicas mais baratos para a produção e imagens a partir de lentes olho de peixe.

Em termos de automação, um dos métodos apontados por Chapaman, Thornes e Bradley (2002) consiste em converter a imagem olho de peixe para o formato digital e em tons de cinza (valores de pixel entre 0 e 255) e utilizar o histograma, com o qual é possível "separar o céu". Nessa técnica sabe-se que os tons de azul do céu são representados em tons mais escuros em uma imagem em preto e branco. Por definição os tons com valor de pixel, superior a 245 representam o céu.

O desenvolvimento dos Sistemas de Informações Geográficas - SIG (Geographic Information System) e seu uso, em várias áreas do conhecimento possibilitou o surgimento de novas técnicas, para a obtenção do FVC. Assim, Santos, Lima e Assis (2003), por exemplo, desenvolveram um método que utiliza os programas Autocad ${ }^{\circledR}$ e Mapinfo ${ }^{\circledR}$ (software de SIG). No primeiro, uma imagem da área de estudo é inserida no programa e desenha-se com uma "polilinha" delimitando o céu visível. No segundo associa-se em tabela o valor do atributo correspondente a cada célula do fator de forma.

O fator de forma, segundo Souza (1997 apud VILELA, 2007, p.62), é um método geométrico que divide a abóbada celeste em círculos e raios, gerando células em que cada unidade é atribuído um valor. Segundo Vilela (2007, p.62), o "Mapinfo é capaz de calcular a área dentro do polígono determinado pela polilinha e atribuir os valores das células do fator de forma, mostrando como resultado a relação entre o céu visível e o céu obstruído, ou seja, o FVC no ponto".

Em seguida, também em ambiente de SIG, Souza (2003) desenvolveu uma técnica que substitui as rotinas tradicionais, automatizando o processo de cálculo do $\mathrm{FVC}$, com a vantagem de permitir a obtenção simultânea do FVC em diversos pontos. Essa técnica foi implantada diretamente no programa ArcView 3.2® (software de SIG), através de uma extensão denominada 3Dskyview, "que tem como princípio básico a sobreposição espacial de uma malha estereográfica de pontos da abóbada celeste sobre a projeção da camada intra-urbana em plano horizontal”. (SOUZA, 2006 p.52).

No uso de fotografias com lentes olho-de-peixe, um dos estudos mais relevantes que buscaram popularizar o seu uso foi o realizado por Mirella, Tamura e Krügger (2009), que demonstraram a possibilidade de utilizar a lente olho-de-peixe acoplada a uma câmera desprovida do sistema Full-frame, de menor custo, através da utilização do software Photoshop para junção de duas imagens obtidas do mesmo ponto, mas com orientações diferentes, eixos perpendiculares, para complementar a total visualização da abóbada celeste.

\section{MATERIAIS E MÉTODOS}

A avaliação das ferramentas sugeridas neste trabalho foi realizada tomando-se como estudo de caso um ponto situado no jardim lateral da biblioteca Campus João Pessoa do IFPB, circundado por três edificações (Figura 02).

Para se obter a máscara de obstrução, inicialmente foi realizado um levantamento topográfico para se obter a locação e a geometria das edificações situadas entorno do ponto considerado (Figura 02). Para o levantamento utilizou-se uma estação total, marca: RUÍDE, modelo RTS-820, além de receptores GNSS de dupla frequência, marca: TOPCON, modelo: Hiper Lite Plus 
Figura 02: Planta Baixa e Cortes da área em estudo.

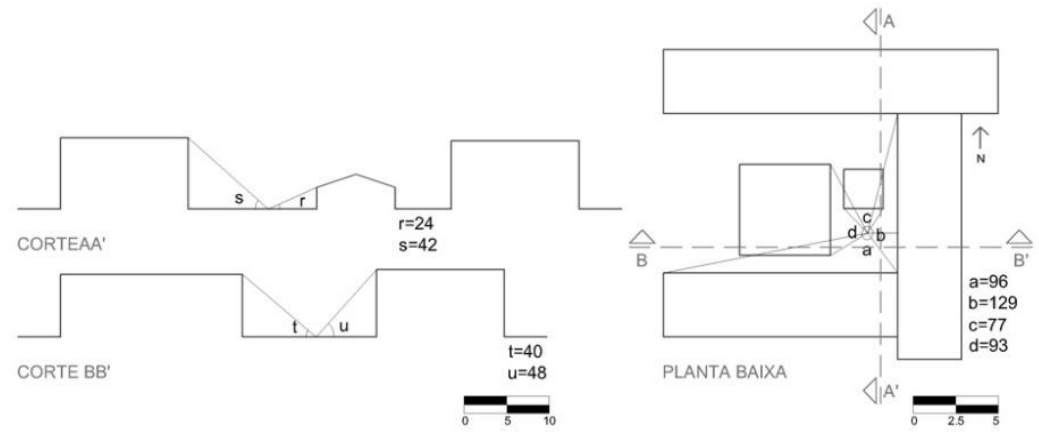

A partir dos dados de referência obtidos no levantamento topográfico, foi desenhada no software Autodesk AutoCAD 2012 a máscara de obstrução e referência, através do método estereográfico (FROTA, 2004).

Num instante seguinte, a mesma máscara foi produzida de forma automatizada, utilizando como ferramenta o software Autodesk ECOTECT 2011, que é bastante utilizado como ferramenta de simulação de desempenho termo-energético de edificações, portanto, tendo sua técnica de produção da máscara de obstrução já validada.

As duas máscaras produzidas inicialmente serviram como referências para a avaliação das máscaras produzidas pelas duas ferramentas testadas nesta por esta pesquisa. A primeira ferramenta corresponde ao software Sketchup Pro 8, com a inserção de dois plug-ins $^{1}$ : o V-ray utilizado para renderização de maquetes eletrônicas e o Sun Tools, que adiciona ao Sketchup algumas ferramentas de análise da geometria da insolação, conforme Figura 03. O Sketchup e o V-ray são softwares amplamente utilizados pelo mercado, o que facilita a implantação da análise da geometria solar na rotina projetual dos escritórios de arquitetura. O Sun Tools é uma ferramenta livre, disponível para download, bastante leve e de fácil utilização.

Figura 03: (a) Interface do software Sketchup com aplicação da ferramenta Sun Path do plug-in Sun Tools no modelo eletrônico desenvolvido para este estudo.

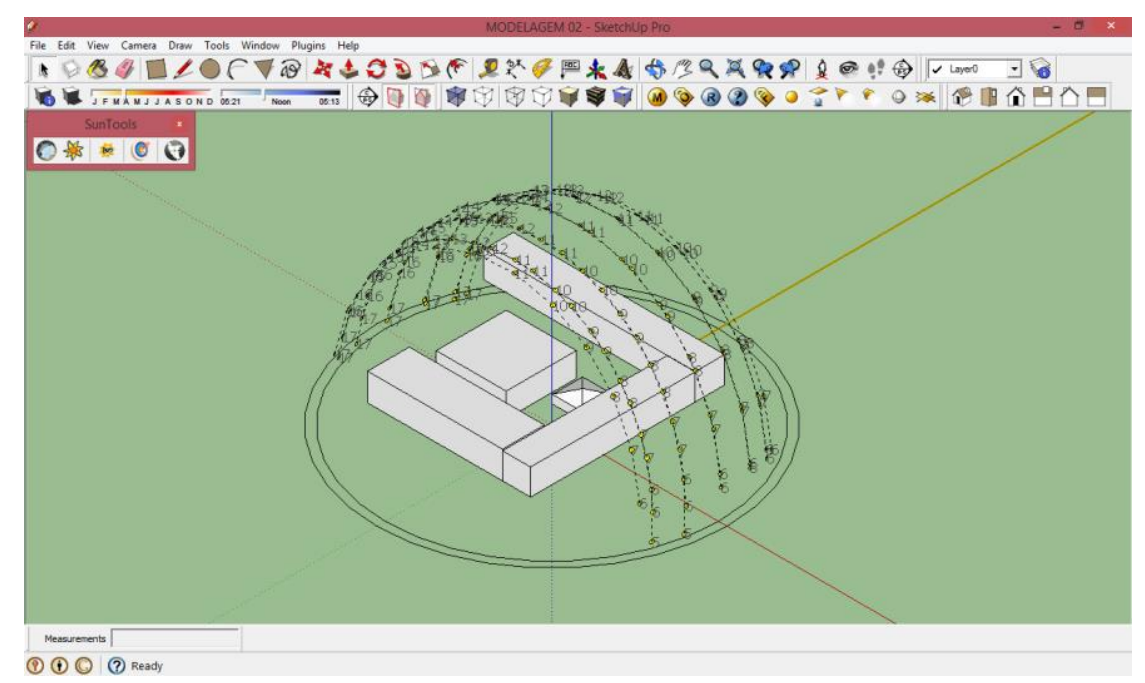

A segunda ferramenta avaliada foi a uma lente olho-de-peixe compacta, marca: Lesung, modelo: FE-19, acoplada a um telefone móvel com câmera, tipo smartphone, marca:

\footnotetext{
${ }^{1}$ Plug-in: é um programa de computador usado para adicionar funções a outro programa maior.
} 
Samsung, modelo: S6802 (Figura 04). O equipamento foi posicionado com o auxílio de um tripé com suporte para telefone móvel e nivelado com uma bolha de nível circular. As fotografias obtidas pelo conjunto óptico foram vetorizadas através do software AutoCAD 2012, assim como, a sobreposição ao diagrama solar.

Figura 04: (a) Lente olho-de-peixe, (b) conjunto utilizado para verificação da máscara de sombra.
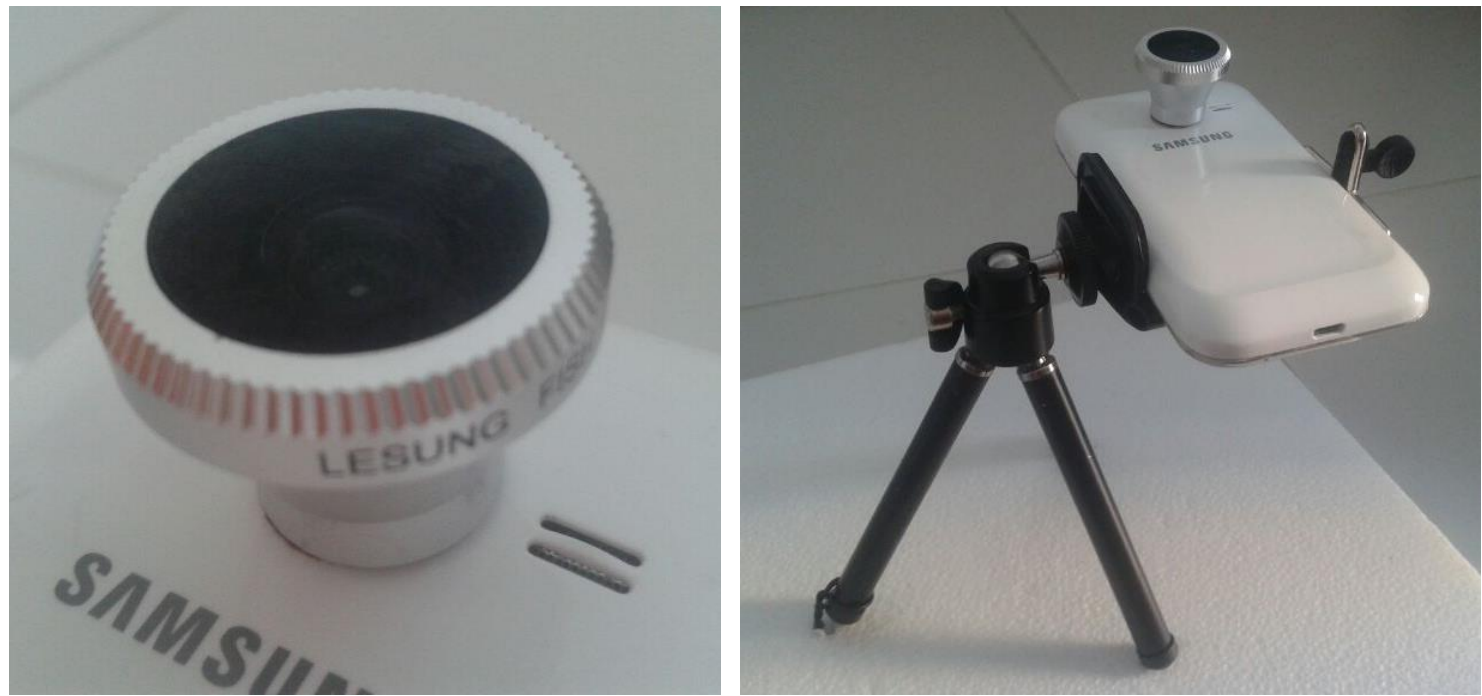

\section{RESULTADOS E DISCUSSÃO}

Com o uso da ferramenta Sketchup é possível modelar a espaço construído e gerar a máscara de obstrução da abóbada celeste com o uso da ferramenta V-ray. Combinando essa máscara com a carta solar produzida através da ferramenta Sun Tools é possível identificar os períodos de exposição (ao sol) do ponto central da máscara de obstrução e das fachadas das edificações em seu entrono (Figura 05a). Essas ferramentas possibilitam a geração de uma perspectiva do ambiente estudado, semelhante à de uma lente olho-depeixe (Figura 05b).

Figura 05: (a) Máscara de sombra gerada pelo Ecotect, (b) Perspectiva gerada a partir de uma câmera olho-de-peixe no Sketchup/ V-ray/ Sun Tools.

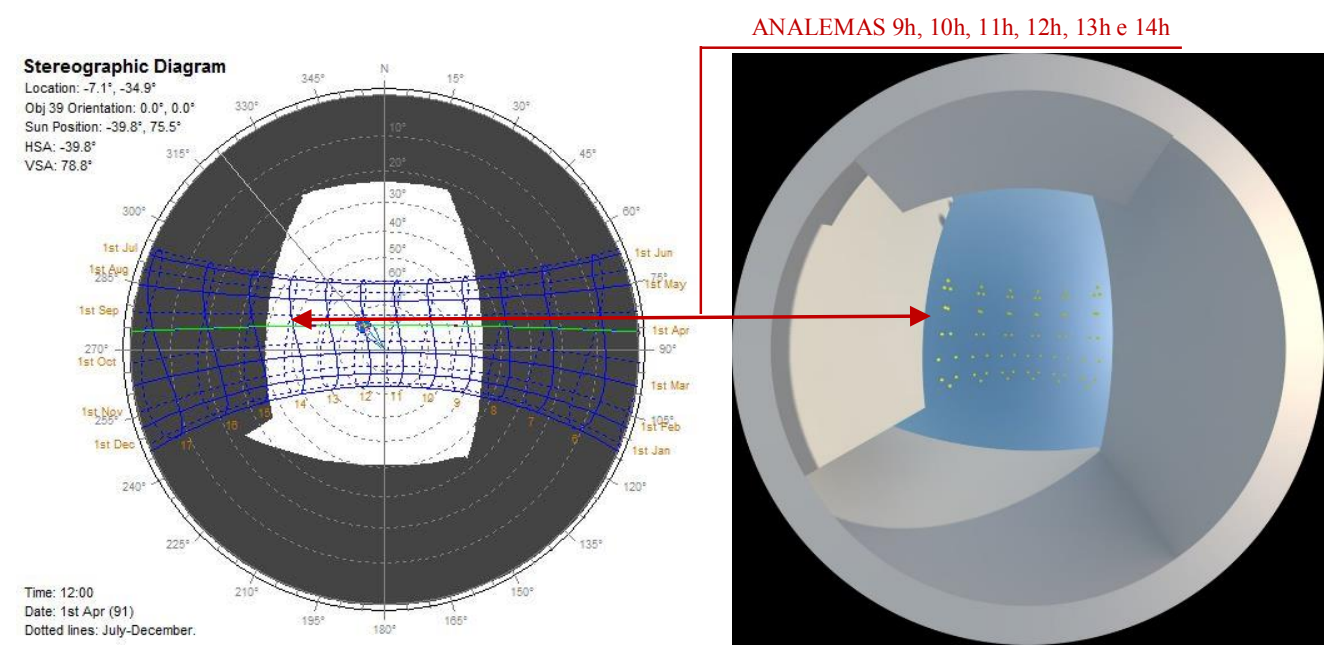


Comparando a máscara de obstrução produzida no Sketchup com as produzidas no CAD e no Ecotect, percebeu-se uma distorção, para mais, ao Norte, o que corresponde, teoricamente, a uma obstrução menor da abóbada celeste (Figuras 07 e 08).

Figura 07: Máscaras de obstrução obtidas pelos diferentes métodos com a indicação do FVC.

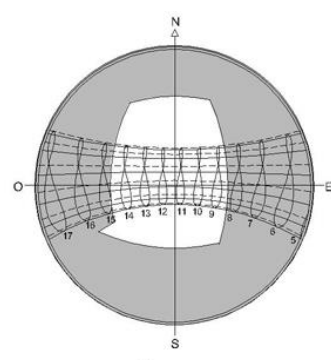

MÉTODO

GRÁFICO

$\mathrm{FVC}=\mathbf{2 6 , 3} \%$

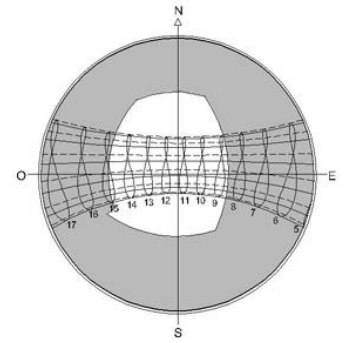

LENTE OLHO-DE-PEIXE

$\mathrm{FVC}=\mathbf{2 5 , 4} \%$

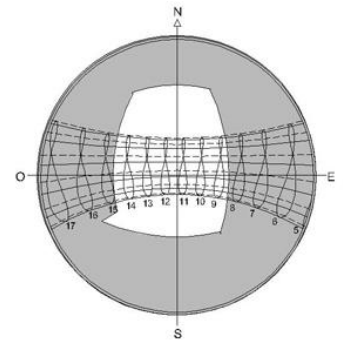

ECOTECT

$\mathrm{FVC}=\mathbf{2 5 , 7} \%$

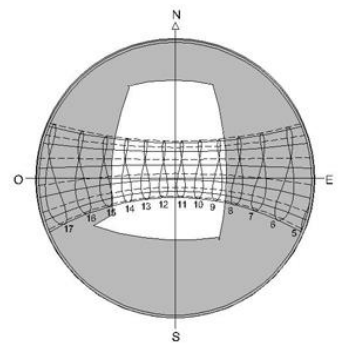

SKETCHUPI

V-RAY

$\mathrm{FVC}=\mathbf{2 7 , 7 \%}$

Figura 08: Sobreposição da parcela da abóbada celeste visível resultante dos diferentes métodos de análise.

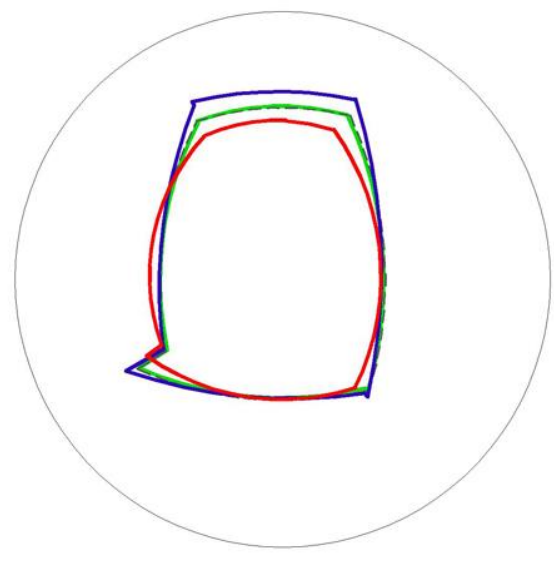

— LENTE OLHO-DE-PEIXE ECOTECT

SKETCHUP/ V-RAY MÉTODO GRÁFICO

A imagem gerada a partir da lente olho-de-peixe para celular (Figura 09) apresentou uma deformação, para menos, na direção Norte, e para mais na direção Oeste. Neste último caso, a deformação correspondeu ao aumento do tempo de exposição à radiação solar direta nos equinócios, em cerca de 20 minutos.

Figura 09: (a) Máscara de sombra pelo método gráfico, (b) Perspectiva gerada a partir de uma lente olho-de-peixe para dispositivos móveis. 

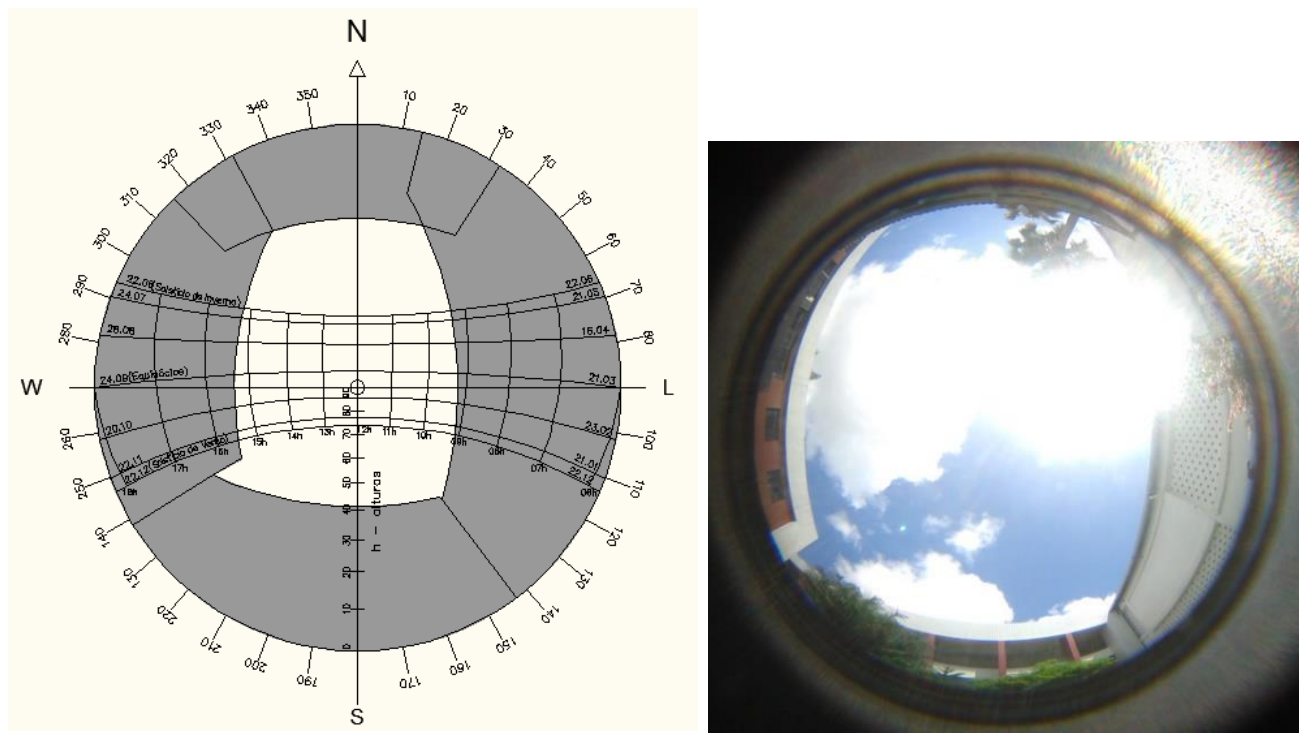

Percebeu-se no uso desta ferramenta que a lente utilizada não atinge, de fato, $180^{\circ}$ de abrangência, portanto, não registrando toda a abóbada celeste. A lente registra apenas os obstáculos situados a ângulos verticais superiores a $20^{\circ}$ do observador em relação ao plano horizontal.

Para se ter uma verificação mais precisa da diferença entre as ferramentas utilizadas, calculou-se o FVC a partir de cada máscara de obstrução produzida, a partir do que constatou-se uma diferença pouco significativa, cerca de $2 \%$, em relação às máscaras de referência, que se faz constatar que as ferramentas testadas são eficazes. Obteve-se com o método gráfico um FVC de $26,3 \%$ e de $25,7 \%$ com o software Ecotect, enquanto, a câmera olho de peixe e o software sketchup, resultaram em um FVC de 25,4\% e 27,7\%, respectivamente.

\section{CONSIDERAÇÕES FINAIS}

Com o surgimento de novos softwares e o aperfeiçoamento dos existentes, assim como o desenvolvimento de interfaces mais amigáveis voltadas aos projetistas, observa-se, cada vez mais, a facilidade de adoção da avaliação das condicionantes climáticas nas fases de projeto. Neste sentido, este artigo demonstrou o potencial de utilização de algumas ferramentas comuns no dia-a-dia dos projetistas para a compreensão da geometria da insolação.

A utilização do software Sketchup permite ao projetista uma avaliação do sombreamento integrada ao processo do estudo do agenciamento, da orientação e da forma. Podendo ser potencializado através da integração com os plug-ins V-ray e Sun Tools, para geração das máscaras de sombras e do diagrama solar, agilizando assim o processo de tomada de decisões.

A imagem gerada pela lente olho-de-peixe acoplada ao celular apresentou a maior deformação em relação aos demais métodos utilizados. Porém, demonstrou ser um método confiável, com a vantagem de não exigir o levantamento físico do entorno e, ainda, de registrar os elementos arbóreos e ou outros elementos de geometria complexa.

Também, devido ao baixo custo da lente, inferior a $\mathrm{R} \$ 30,00$, e a popularização dos smartphones, acredita-se que a sua utilização por estudantes e profissionais tem grande potencial, pois requer uma técnica bastante simples e de maior agilidade, se comparada 
ao uso de equipamentos de fotografia mais sofisticados (profissionais), além de não requerer o levantamento do entorno, necessário no uso das técnicas automatizadas.

\section{AGRADECIMENTOS}

Ao Laboratório de Topografia e Geodésia do IFPB, por auxiliar na execução do levantamento físico da área em estudo.

\section{REFERÊNCIAS}

BITTENCOURT, L. Uso das Cartas Solares: diretrizes para arquitetos. 4. ed. Maceió: EDUFAL, 2004.

FROTA, A. B.. Geometria da Insolação. - 1.ed. - São Paulo:Geros, 2004.

GRAZZIOTIN, P. C. Técnicas de incorporação de controle de acesso à luz solar em modelos computacionais. Dissertação de Mestrado. UFRG, Porto Alegre, 2003 Disponível em: $<$ http://www.lume.ufrgs.br/bitstream/handle/10183/7843/000558332.

pdf?sequence $=1>$. Acesso: $22 / 12 / 2008$.

MINELlA, F. O.; TAMURA, C. A.; KRÜGER, E. L. Apresentação de método fotográfico para obtenção do fator de visão do céu. In: Encontro Nacional, 10., e Encontro Latino-Americano Sobre Conforto no Ambiente Construído, 9., 2009, Natal. Anais... Natal, ANTAC, 2009.

SANTOS, I. G.; LIMA, H. G.; ASSIS, E. S.; Influência da geometria urbana e da inércia térmica na alteração do clima urbano: uma abordagem preditiva VII ENCAC Curitiba - PR, Brasil 2003.

SIGNORINI, V. B.; BERGER, J.; HILLER, R. CORREA, C. B. Estudo comparativo de métodos de predição de sombreamento em edificações. In: Congresso LusoBrasileiro para o Planejamento Urbano, Regional, Integrado e Sustentável, 5. 2011. Brasília. Anais... Brasília, ANPET, 2011.

SOUZA, L. C. L. Determinação e apresentação do fator de visão do céu através de um SIG 3 D. Bauru. Livre-docência - Faculdade de Arquitetura, Artes e Comunicação da Universidade de São Paulo, 2003.

SOUZA, L. C. L; POSTIGO, C. P. Ambiente térmico urbano: verticalização, acesso solar e a formação de ilhas de calor. 2007.

SOUZA, L. C. L.; PEDROTTI, F.S.; LEMES, F. T. Consumo de energia urbano: Influência do perfil do usuário; da geometria urbana e da temperatura. Maceió, 2005.

VILELA J. A. Variáveis do clima urbano: análise da situação atual e prognósticos para a região do bairro Belvedere III, Belo Horizonte, MG. Dissertação de Mestrado. UFMG. $2007 . \quad$ Disponível em: $<$ http://www.bibliotecadigital.ufmg.br/dspace/bitstream/1843/RAAO7BRFXX/1/dissert a_o_jacqueline_vilela.pdf $>$. Acesso em: 22/10/2008. 